\title{
Combined Epidermal Growth Factor Receptor and Beclin1 Autophagic Protein Expression Analysis Identifies Different Clinical Presentations, Responses to Chemo- and Radiotherapy, and Prognosis in Glioblastoma
}

\author{
Paolo Tini, ${ }^{1,2,3}$ Giuseppe Belmonte, ${ }^{1,3,4}$ Marzia Toscano, ${ }^{1,3}$ Clelia Miracco,, 1,3,4 \\ Silvia Palumbo, ${ }^{5}$ Pierpaolo Pastina, ${ }^{1,3}$ Giuseppe Battaglia, ${ }^{1,3}$ Valerio Nardone, ${ }^{1,3}$ \\ Marie Aimée Gloria Munezero Butorano, ${ }^{3,4}$ Armando Masucci, ${ }^{6}$ \\ Alfonso Cerase, ${ }^{7}$ and Luigi Pirtoli ${ }^{1,2,3}$ \\ ${ }^{1}$ Tuscan Tumor Institute (ITT), 50139 Florence, Italy \\ ${ }^{2}$ Unit of Radiation Oncology, University Hospital of Siena, 53100 Siena, Italy \\ ${ }^{3}$ Department of Medicine, Surgery and Neurological Sciences, Research Center for Molecular Radiobiology, University of Siena, \\ 53100 Siena, Italy \\ ${ }^{4}$ Unit of Pathological Anatomy, Department of Medicine, Surgery and Neurological Sciences, University of Siena, 53100 Siena, Italy \\ ${ }^{5}$ Department of Biology and Biotechnology, University of Pavia, 27100 Pavia, Italy \\ ${ }^{6}$ Unit of Preventive Medicine, Moscati Hospital, 83100 Avellino, Italy \\ ${ }^{7}$ Unit of Neuroradiology, University Hospital of Siena, 53100 Siena, Italy
}

Correspondence should be addressed to Paolo Tini; paolo-tini@libero.it

Received 18 July 2014; Accepted 1 October 2014

Academic Editor: Saverio Bettuzzi

Copyright (C) 2015 Paolo Tini et al. This is an open access article distributed under the Creative Commons Attribution License, which permits unrestricted use, distribution, and reproduction in any medium, provided the original work is properly cited.

\begin{abstract}
Dysregulated EGFR in glioblastoma may inactivate the key autophagy protein Beclinl. Each of high EGFR and low Beclinl protein expression, independently, has been associated with tumor progression and poor prognosis. High $(\mathrm{H})$ compared to low (L) expression of EGFR and Beclin1 is here correlated with main clinical data in 117 patients after chemo- and radiotherapy. $\mathrm{H}$ EGFR correlated with low Karnofsky performance and worse neurological performance status, higher incidence of synchronous multifocality, poor radiological evidence of response, shorter progression disease-free (PDFS), and overall survival (OS). H-Beclin1 cases showed better Karnofsky performance status, higher incidence of objective response, longer PDFS, and OS. A mutual strengthening effect emerges in correlative power of stratified L-EGFR and H-Beclinl expression with incidence of radiological response after treatment, unifocal disease, and better prognosis, thus identifying an even longer OS group (30 months median OS compared to 18 months in L-EGFR, 15 months in H-Beclinl, and 11 months in all GBs $)(P=0.0001)$. Combined L-EGFR $+\mathrm{H}$-Beclinl expression may represent a biomarker in identifying relatively favorable clinical presentations and prognosis, thus envisaging possible EGFR/Beclinl-targeted therapies.
\end{abstract}

\section{Introduction}

Glioblastoma (GB) is the most frequent primary brain neoplasm and one of the most lethal tumors. Standard treatment is the maximal safe surgical resection followed by adjuvant radiotherapy (RT) and chemotherapy (CHT) [1]. Despite this multimodal treatment, prognosis remains poor, with less than $5 \%$ of the patients alive beyond five years from diagnosis [2]. Extensive multiplatform genomic characterization is increasing our understanding of the molecular bases of GB and is leading to the discovery of promising novel therapeutic targets, although efficient new treatments are still not available [3-5]. 
Epidermal growth factor receptor (EGFR) gene mutations, amplification and overexpression, EGFR protein overexpression, and PI3K-Akt-mTOR-EGFR pathway dysregulation are hallmarks of GB, usually related to an aggressive phenotype [6] and characterize the most frequent GB molecular subtype showing the classical expression profile [7].

The PI3K-Akt-mTOR signaling pathway, driven or not by EGFR activation, negatively regulates autophagy [8]. Autophagy is a degrading, self-eating cellular process involved in an array of physiological and paraphysiological cellular functions [9]. Its relevance is emerging also in cancer, in which, based on cell context, tumor type, and stage, autophagy may play different roles [10]. While autophagy halts tumor initiation, in advanced cancer it can either promote tumor progression, allowing cell survival, or lead to cell death [11]. Autophagy-related death, also known as "type II programmed cell death," has been recognized as a major type of nonapoptotic death in GB, both in vivo [12] and in vitro [13], being induced by RT and CHT [14, 15]. Thus, novel autophagy-based GB treatment approaches may be envisaged. Therapeutic perspectives also derive from the complex crosstalk between autophagy genes and apoptotic and other types of cell death $[16,17]$. The autophagic gene Beclin1 and its complex with either $\mathrm{Bcl} 2$ or $\mathrm{Vps} 34$, the Class III PIK involved in autophagosome initiation, are key determinants of autophagy and cell fate [18].

Beclinl also binds EGFR [19] and EGFR is able to directly regulate Beclin1 and autophagy also in an mTORindependent manner [19]. EGFR promotes tumor growth and cell motility [20] and has been associated with a poor clinical GB outcome and unfavorable GB presentation [21]. Beclinl expression, instead, decreases with tumor progression $[22,23]$, and we observed also that it is positively correlated with a better GB patient clinical outcome [24]. In a recent study, we found that the modulation of autophagy and EGFR expression has an impact on GB cell migration activity and response to radiation treatment [25].

We are not aware of previous studies correlating EGFR and Beclin1 expression with clinical features in GB. Here, we retrospectively analyzed the potential relevance of concomitant Beclinl and EGFR protein expression and examined their colocalization in a series of patients affected by GB, aiming at investigating clinical implications of the patterns of their expression in GB tissue, out of a patient series undergoing postoperative CHT-RT.

\section{Materials and Methods}

2.1. Ethics Approval. This study was approved by both the Institutional Review Board and Ethics Committee of the University Hospital of Siena, and all the patients had provided signed informed consent before any treatment.

2.2. Patients. We retrospectively reviewed the medical records of patients affected by GB (Grade IV-WHO Classification [26]) submitted to the Radiation Oncology Unit of the University Hospital of Siena for postoperative adjuvant CHT-RT from February 2002 to November 2013. Patients who had undergone a full-course RT and CHT (i.e., standard RT and concurrent and sequential temozolomide (TMZ) administration) were included in the study, whereas patients enrolled in clinical trials with experimental RT/CHT with antiangiogenetic, anti-EGFR, and any other targeted therapy were excluded.

Patients were referred, treated, and followed up on a three-month interval basis after therapy in our unit. All clinical and pathological data were recorded, including extent of surgery and histological diagnosis, clinical examination, blood counts and chemistry, Karnofsky performance status (KPS), neurological performance status (NPS), chest Xray, and pre- and postoperative and follow-up magnetic resonance imaging (MRI).

2.3. Postoperative Treatment. RT and TMZ CHT schedules were adopted as previously described, according to a protocol-driven schedule [27]. Briefly, RT consisted of a 54$60 \mathrm{~Gy}$ total dose administered with three-dimensional conformal irradiation in all cases with a unifocal presentation. The planning target volume (PTV) [28] included residual tumor mass and postoperative cavity with a $2-3 \mathrm{~cm}$ margin. Suitable patients with small lesions received a boost dosage up to $70 \mathrm{~Gy}$, limited to the gross tumor volume (GTV) [28] if no obvious progression or relevant toxicity occurred during the previous irradiation course. Patients with multifocal lesions were submitted to whole brain irradiation, up to $50 \mathrm{~Gy}$. Five weekly 1.8-2 Gy sessions were administered during the entire RT course, in all cases. All patients received TMZ concurrent with RT $(75 \mathrm{mg} / \mathrm{mq} / \mathrm{die})$ up to a maximum of 7 weeks, and most of them also received sequential TMZ CHT (150-200 mg/mq for 5 days, every 28 days), unless tumor progression or relevant toxicity occurred. The patients included in this evaluation completed at least $80 \%$ of the planned treatment.

2.4. Follow-Up. After treatment, all patients were included in a follow-up program. General and neurological examinations, with blood counts and chemistry, were performed every three months, as previously outlined.

2.5. Clinical Variables Included in the Study. Age: A cut-off value of 50 years $(\leq 50 \mathrm{y},>50 \mathrm{y})$ was established according to literature [2].

KPS: Two categories were considered, $100-80 \%$; $\leq 70 \%$, after surgery.

NPS: Patients were assigned to five categories after surgery (1: no neurological impairment; 2: some neurological impairment; 3: moderate impairment; 4: major functional impairment; 5: no conscious response), according to the Medical Research Council Brain Tumor Working Party [29].

MRI disease presentation (unifocal versus synchronous multifocal disease) was assessed at the preoperative MRI examination. Multifocality consisted of at least two lesions at the gadolinium-enhanced $\mathrm{T} 1$ sequence, separated by a distance of at least $1 \mathrm{~cm}$.

After RT and concurrent TMZ administration, MRI was repeated, in order to assess the subsequent tumor volume evolution with respect to pre-RT status, the first time at 2-3 
weeks after completion, then on a 3-month basis, and in any case of suspicion of tumor progression on clinical grounds.

Radiological response (RR) was so detected and classified into complete response (CR), partial response (PR), stable disease (SD), and progressive disease (PD) at the first MRI examination. Objective response is defined as $\mathrm{OR}=\mathrm{CR}+$ PR. RR was assessed using either MacDonald's criteria [30]or response assessment in neurooncology (RANO) criteria [31], respectively, before and after 2010 .

2.6. Molecular Determination of the Methylation Status of the MGMT Gene Promoter. MGMT gene promoter methylation was assessed by methylation-specific polymerase chain reaction (PCR). Briefly, genomic DNA was extracted from paraffin-embedded tumor sections and treated with sodium bisulfite using the EZ DNA Methylation-Gold kit (HISS Diagnostics, GmbH, Freiburg, Germany). Primer sequences were used to detect methylated and unmethylated MGMT promoter sequences. PCR products were separated on $2 \%$ agarose gel. A glioma cell line, with a completely methylated MGMT promoter, and peripheral blood mononucleated cells served as positive and negative control samples, respectively.

2.7. EGFR and Beclin1 Immunohistochemistry. In each case, $3 \mu \mathrm{m}$ thick sections were cut from paraffin blocks of $10 \%$ formalin-fixed tumor fragments and processed for immunohistochemistry. Briefly, after deparaffinization and rehydration, before applying the anti-EGFR mouse monoclonal (clone EGFR.25, ready to use, and catalogue number: RTUEGFR-384, Novocastra, Milan, Italy) or the anti-Beclin1 rabbit polyclonal (gene ID: 8678, amino acids 329-345, diluted $1: 200$, and catalogue number: B6186, Sigma-Aldrich, Milan) primary antibodies, sections were pretreated either with Pronase XIV of Streptomyces griseus (Bio-Optica, Milan, Italy) at $37^{\circ} \mathrm{C}$ for 10 minutes or with WCAP citrate buffer $\mathrm{pH}$ 6.0 (Bio-Optica), for $40 \mathrm{~min}$ at $98.5^{\circ} \mathrm{C}$, respectively.

The evaluation of the signal was performed by UltraVision LP Large Volume Detection System HRP Polymer (Bio-Optica, Milan), with the diaminobenzidine chromogen (Dako) for $8 \mathrm{~min}$. Sections were then counterstained with Meyer's hematoxylin. In all cases, negative controls were performed by repeating the procedure and omitting the primary antibody.

2.8. Assessment of Immunostaining. Staining was independently evaluated by two of the authors (CM, MAGMB), at medium resolution (20x objective, eye piece 1.25$)$ all throughout tumor sections. EGFR membranous and/or cytoplasmic and Beclin1 cytoplasmic immunoreactivity scored 0 if negative and from 2 to 5 , if positive, on the basis of both the stain's intensity (1: weak, 2: moderate, and 3: strong) and the percentage of positive cells $(1: \leq 50 \%, 2:>50 \%)$. We considered scores $0-2$ as a low $(\mathrm{L})$ and scores $3-5$ as a high $(\mathrm{H})$ protein expression, respectively.

2.9. Double EGFR-Beclin1 Immunofluorescence Stain. In order to colocalize EGFR and Beclin1 protein in tumor cells, in representative cases of each group of low or high protein expressing GBs, a double immunofluorescence stain was performed. Briefly, $4 \mu \mathrm{m}$ thick sections were deparaffinized in xylene and rehydrated in graded ethanol solutions $(100 \%$, $95 \%, 80 \%$, and 70\%), 5 minutes each, and washed in $\mathrm{dH}_{2} \mathrm{O}$. Then, antigen retrieval was obtained by incubation with $10 \mathrm{mM}$ sodium citrate buffer $(\mathrm{pH} 6.0)$ at a subboiling temperature for $20 \mathrm{~min}$. Sections were then cooled for $10 \mathrm{~min}$, washed in phosphate-buffered saline (PBS), and incubated overnight at $4^{\circ} \mathrm{C}$ with the following antibodies: mouse antiEGFR (Undiluted, Novocastra); rabbit anti-Beclin1 (diluted 1:200, Sigma-Aldrich). The slides were washed three times with PBS and incubated with the secondary antibody fluorochrome conjugate (goat anti-rabbit Alexa Fluor 488, goat anti-mouse Alexa Fluor 568) for 1 hour at room temperature in the dark. The nuclei were counterstained by incubating the sections for $10 \mathrm{~min}$ with $4^{\prime}, 6$-diamidino2-phenylindole (DAPI). Slides were washed in PBS and mounted with Antifade. In each case, a negative control was generated by omitting the primary antibody. Images were acquired and analyzed with a microscope Leica AF CTR6500HS (Microsystems).

2.10. Western Blotting. Tissue samples were lysed in radioimmunoprecipitation assay (RIPA) buffer containing protease inhibitors, following standard procedures. After protein determination, using BioRad protein assay (BioRad, Milan, Italy), equal amounts of proteins $(40 \mu \mathrm{g})$ were resolved on $8 \%$ SDS-PAGE gel and transferred to a nitrocellulose membrane (BioRad). Membranes were blocked with 3\% nonfat milk (BioRad) in PBS Tween $0.05 \%$ (PBST) and incubated overnight at $4^{\circ} \mathrm{C}$ with the following antibodies: antiEGFR (undiluted, Novocastra), anti-Beclin1 (1:270, SigmaAldrich), and anti- $\beta$-actin (1:500, catalogue number: 041116, MERCK Millipore Corporation, Billerica, MA, US) diluted with $3 \%$ nonfat milk in PBST. Membranes were washed three times in PBS Tween $0.1 \%$ and incubated with specific secondary antibodies diluted with $3 \%$ nonfat milk in PBST (goat anti-rabbit IgG $(\mathrm{H}+\mathrm{L})$-HRP conjugate, diluted $1: 10000$, catalogue number: 172-1019, BioRad; goat antimouse IgG $(\mathrm{H}+\mathrm{L})$-HRP conjugate, diluted 1:5000, catalogue number: 172-1011, BioRad) for $1 \mathrm{~h}$ at RT. The membranes were incubated with ECL reagents (BioRad) for $1 \mathrm{~min}$ and then were developed on Hyperfilm ECL (Amersham GE Healthcare, 28906835).

Images of the bands were digitized and the densitometry was performed using the open source image processing program ImageJ (http://imagej.nih.gov/ij/); $\beta$-actin bands were used for normalization.

2.11. Statistical Analysis. We performed a correlation analysis using Spearman's rho two-tailed correlation test between clinical parameters and L- and H-EGFR/Beclin1-expression groups. Overall and progressive disease-free survival (OS and PDFS, resp.) were calculated with the Kaplan-Meier method. The univariate survival analysis was used to identify prognostic parameters as follows: clinical factors (age, KPS, NPS, and synchronous multifocality), treatment-related factors (extent of surgery, RT dose, sequential TMZ, and radiological response from MRI scans), and biological factors (EGFR/Beclin1 protein expression). 


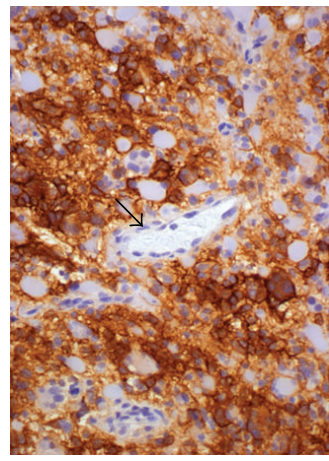

(a)

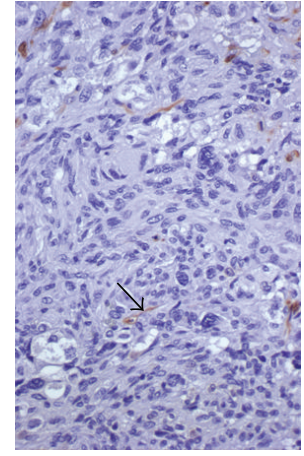

(b)
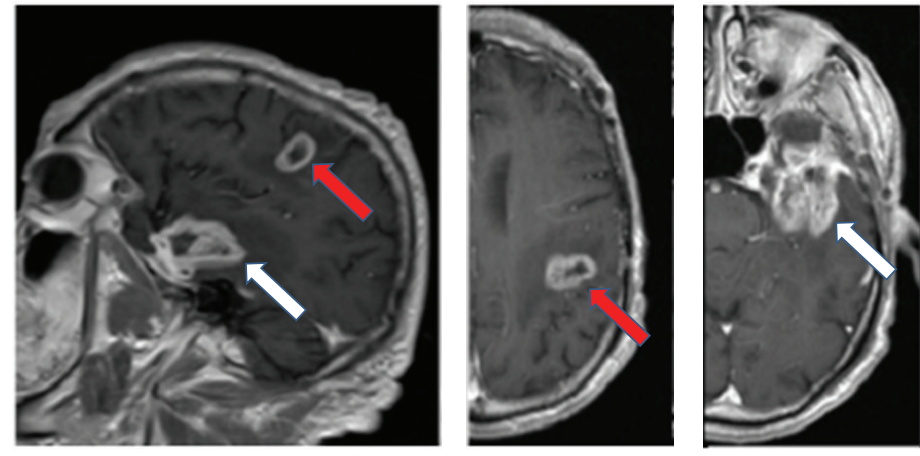

(c)

FIGURE 1: Patient with H-EGFR (a) and L-Beclin1 (b) pattern of protein expression in a GB. The arrows indicate the endothelium of vessels, negative for EGFR (a) and positive for Beclinl (b) Immunohistochemistry, diaminobenzidine, original magnification $\times 200$. The MRI T1sequence with gadolinium (c) shows a multifocal GB with a left temporal (white arrow) and a parietooccipital lesion (red arrow).

We used the log-rank test to assess the significance of survival differences for the considered parameters $(P$ values $\leq 0.05$ were considered as statistically significant). We also performed a multivariate analysis (Cox regression) to quantify the relationship between survival and potential predictors, in order to identify a subgroup of independent factors significantly related to survival. All statistical analyses were performed with the SPSS 15.0 software package for Windows.

\section{Results}

3.1. Patients and Postoperative Treatment. One hundred and seventeen patients were included in this study, all planned for RT and concurrent TMZ. At surgery, 23 had a gross tumor resection (GTR) (19.7\%) and $94(80.3 \%)$ a biopsy or a subtotal tumor resection (B-STR), respectively. Median age was 62 years (range $26-83$ ), 15 patients $(12.8 \%)$ were $\leq 50 \mathrm{y}$, and the other 102 were $>50 y(87.2 \%)$. The KPS score was $100-80$ in 91 patients $(77.8 \%)$ and $\leq 70$ in $26(22.2 \%)$. The NPS score, at admission, was $1-2$ in 61 patients (52.1\%), 3 in 34 patients (29.1\%), and 4 in 22 patients (18.8\%). Preoperative MRI showed a single tumor in 98 out of 117 patients $(83.8 \%)$ and a multifocal presentation in 16 patients (16.2\%) (Figure $1(\mathrm{c})$ ).

Forty-three patients (36.6\%) received a RT dose of $<54$ Gy (due to a multifocal presentation or constraints, such as critical structures very close to the tumor), 47 (33.8\%) a dose of 54-60 Gy, and $27(23.7 \%)$ a boost up to $70 \mathrm{~Gy}$, according to the aforementioned protocol. Ninety-one (77.6\%) patients completed the full-course of TMZ concurrently to RT; out of them, sequential TMZ was then administered in 76 patients $(64.9 \%)$, until the events of tumor progression or severe toxicity $(64.9 \%)$, whereas $41(35.1 \%)$ patients did not have this treatment scheduled, due to early tumor progression or toxicity at the end of the concurrent RT and TMZ administration.

3.2. Results of Treatment. After RT and concurrent TMZ, the RR demonstrated that 19 patients (16.2\%) had a CR, 26 (22.2\%) a PR (thus an OR was achieved in 45 patients, $38.5 \%$ ), and $25(21.4 \%)$ a SD, whereas $47(40.2 \%)$ experienced a PR at the post-RT MRI controls. The median OS was 11 months; 1-year and 2-year OS values were, respectively, $47.8 \%$ and $25.4 \%$. The median PDFS was 10 months $(39.6 \%$ at 1 year and $27.0 \%$ at 2 years, resp.).

3.3. Methylation Status of MGMT Gene Promoter. MGMT methylation status was assessed in 83 patients: the MGMT promoter was unmethylated in 45 cases (54.2\%) and methylated in 38 (45.8\%).

3.4. EGFR and Beclin1 Immunohistochemistry. EGFR membranous and/or cytoplasmic positivity was observed in most GBs, while few nuclei were decorated by EGFR in a minority of cases. Some cases were completely negative for EGFR. EGFR staining was not observed in vessel endothelia or in normal/reactive glia (Figures 1(a), 2(a), and 3(a)). On the other hand, Beclin1 stained normal cells and was heterogeneous in GBs, with a higher number of cases negative or lowly expressing the protein; a pin point cytoplasmic staining and variable nuclear immunopositivity were observed (Figures 1(b), 2(b), and 3(b)). In several cases, a heterogeneous expression of both proteins was observed in limited areas.

3.5. Assessment of Immunostaining Patterns and Double EGFR-Beclin1 Immunofluorescence Stain. There were 68 cases (58\%) expressing H-EGFR; 49 (41.7\%) expressing L-EGFR; 59 (50.4\%) expressing L-Beclin1, and 58 (49.6\%) expressing $\mathrm{H}$ Beclin1.

Overall, two main immunoreactivity patterns were observable: H-EGFR/L-Beclin1 (34 cases, 29.1\%; Figures 1, 4(a), 4(b), and 4(c)) and L-EGFR/H-Beclin1 (24 cases, 20.5\%; Figures 2, 4(d), 4(e), and 4(f)), the former being the dominant pattern in the majority of cases, although there was a large stain heterogeneity. In fact, there were also cases either highly (H-EGFR/H-Beclin1; Figures 4(g), 4(h), and 4(i)) or lowly expressing (L-EGFR/L-Beclin1; Figures 3, 4(j), $4(\mathrm{k})$, and $4(\mathrm{l}))$ the two proteins. Furthermore, several cases showed heterogeneous expression of both proteins in limited areas (Figure 5). EGFR and Beclin1 protein expressions were mutually exclusive in large areas in many cases. This was more 


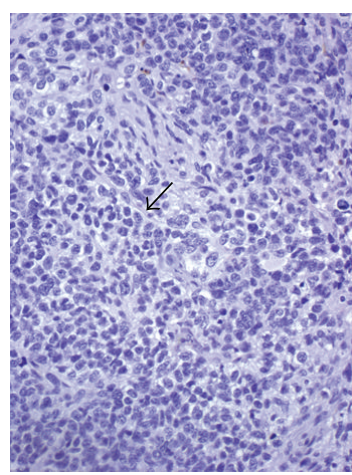

(a)

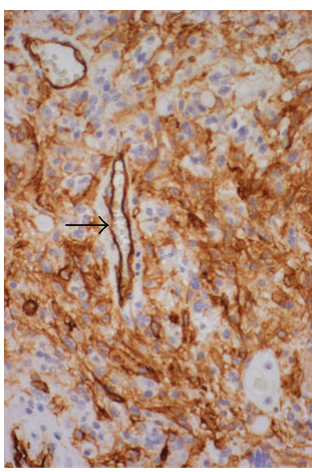

(b)

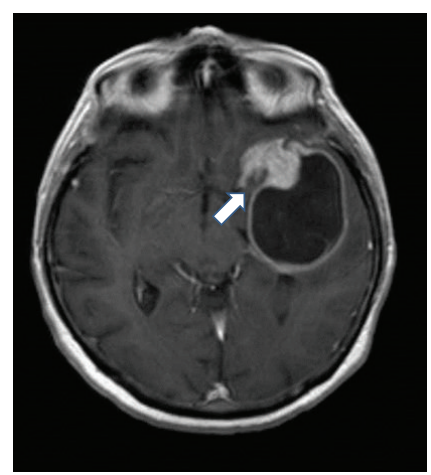

(c)

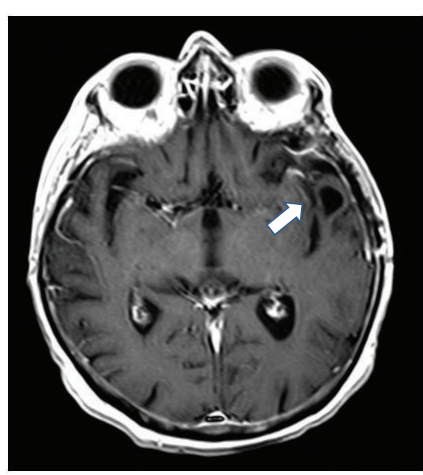

(d)

FIGURE 2: L-EGFR (a) and H-Beclin1 (b) patterns of protein expression in a GB. The arrows indicate the endothelium of vessels, negative for EGFR (a) and positive for Beclin1 (b) Immunohistochemistry, diaminobenzidine, original magnification $\times 200$. (c) MRI T1-sequence with gadolinium shows a left temporal glioblastoma (white arrow) before treatment. (d) Radiological complete response (white arrow) after treatment (MRI at 4 months after adjuvant RT-CHT treatment).

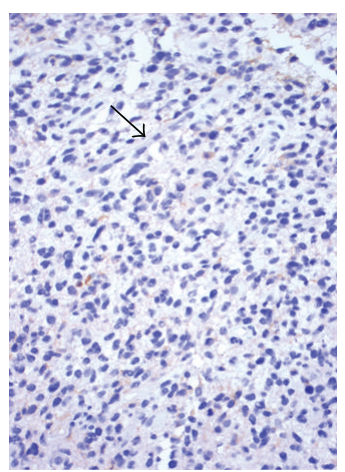

(a)

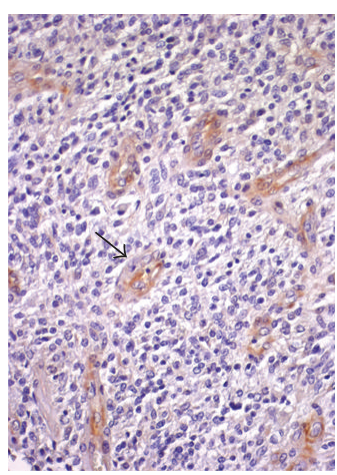

(b)

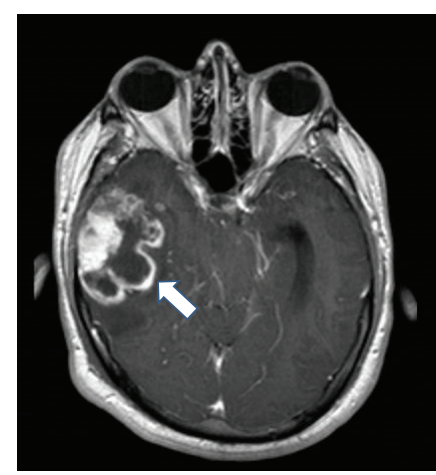

(c)

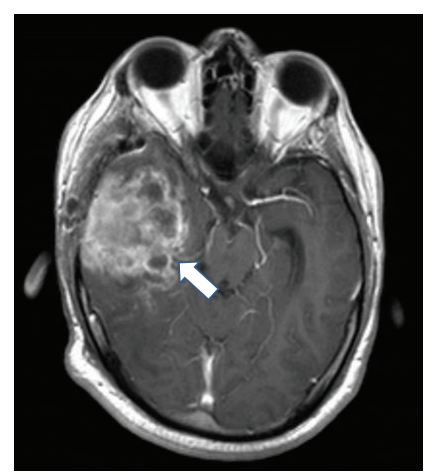

(d)

Figure 3: Patient with L-EGFR (a) and L-Beclin1 (b) pattern of protein expression in GB. The arrows indicate the endothelium of vessels, negative for EGFR (a) and positive for Beclin1 (b) Immunohistochemistry, diaminobenzidine, original magnification $\times 200$. (c) MRI T1sequence with gadolinium shows a right temporal lesion (white arrow) before treatment. (d) Radiological progression (white arrow) after treatment (MRI at 6 months after adjuvant RT-CHT treatment).

evidenced by the double EGFR-Beclin1 immunofluorescence stain (Figure 5).

3.6. Western Blotting. Specific EGFR $(170 \mathrm{kDa})$ and Beclin1 $(60 \mathrm{kDa})$ bands were detected and high versus low protein expression was confirmed in several cases, representative of H-EGFR/L-Beclin1, L-EGFR/H-Beclin1, H-EGFR/HBeclinl, and L-EGFR/L-Becinl groups of patients (Figure 6).

\subsection{Statistics}

3.7.1. Univariate Analysis. Distribution of EGFR and Beclin1 protein expression according to age, KPS, NPS, RMN disease presentation, extent of surgery, data regarding local tumor control, and significant $P$ values are shown in Table 1.

PDFS and OS were negatively correlated with age $(P=$ 0.035 and 0.04 , resp.), KPS $(P=0.001)$, NPS $(P=0.0001)$, synchronous multifocality at preoperative MRI $(P=0.001)$, extent of surgical resection $(P=0.0001$ and 0.001 , resp.), radiation dose $(P=0.04$ and 0.033 , resp.), and sequential $\operatorname{TMZ}(P=0.0001$ and 0.001 , resp. $)$ (Table 2$)$.
EGFR and Beclinl expressions were not correlated with each other. H-EGFR significantly correlated with low KPS $(P=0.03)$, a worse NPS class $(P=0.002)$, a synchronous multifocal presentation $(P=0.01)$ (Figure $1(\mathrm{c}))$, a worse RR $(P=0.013)$, a shorter PDFS $(P=0.002)$, and OS $(P=0.004)$. $\mathrm{H}$-EGFR versus L-EGFR patients had, in fact, a worse median PDFS (5 months versus 14 months) and OS (9 months versus 18 months) (Figure 7).

$\mathrm{H}$-Beclin1 was instead positively correlated with a better KPS $(P=0.009)$, a higher OR $(P=0.002)$, and a better PDFS and $\operatorname{OS}(P=0.001)$.

$\mathrm{H}$-Beclin1 patients had a median OS of 15 months, compared to 5 months for the L-Beclinl group (Figure 8). Clustering L-EGFR and H-Beclin1 expression resulted in a stronger correlation with a better RR $(P=0.001)$ (Figures 2(c) and 2(d)) than other patterns of expression (Figures 3(c) and 3(d)) and absence of MRI multifocality of disease at onset $(P=0.002)$. In particular, no multifocal disease was found in this subgroup of patients.

Clustering EGFR expression and Beclin1, we found that H-Beclin1/L-EGFR had a significantly better prognosis, with 


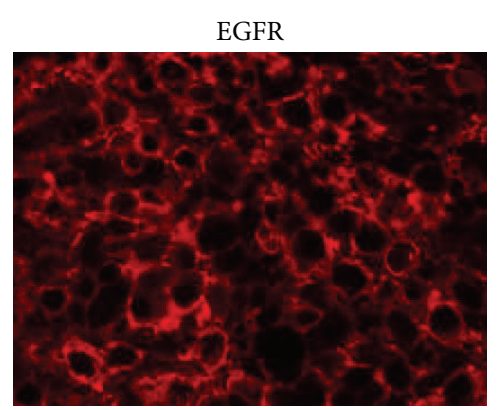

(a)

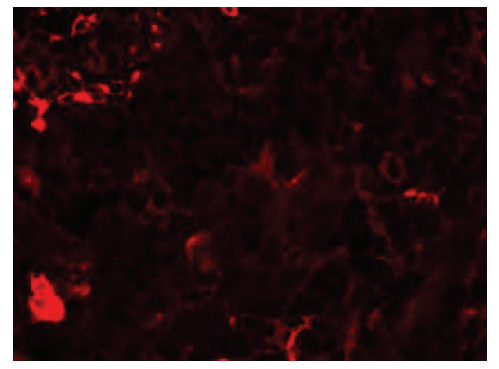

(d)

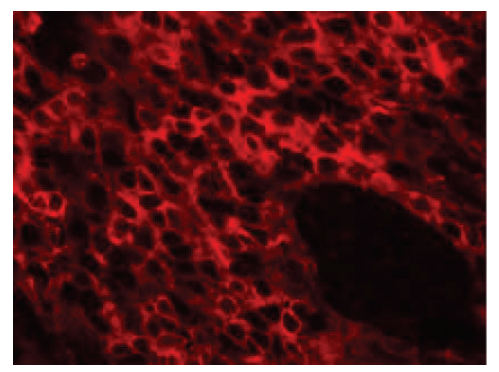

(g)

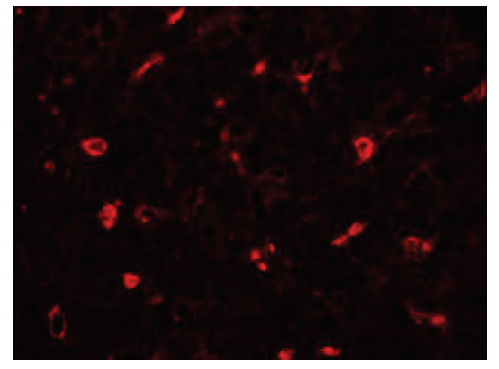

(j)

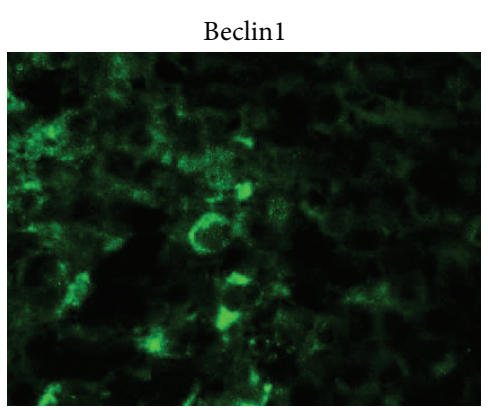

(b)

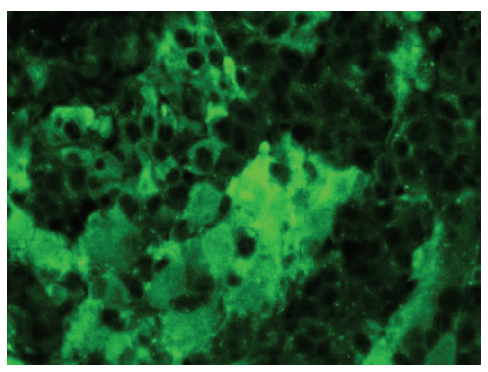

(e)

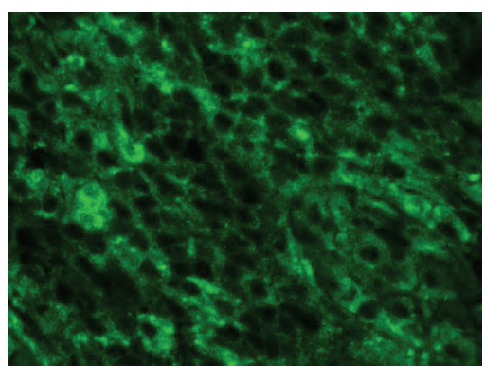

(h)

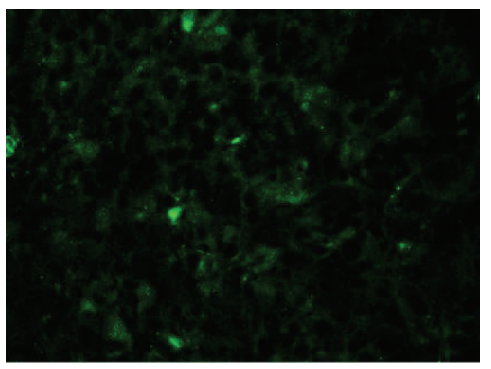

(k)

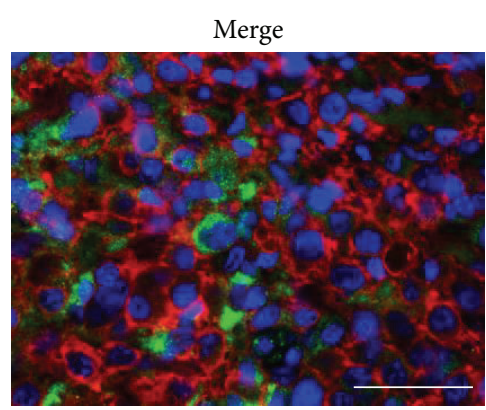

(c)

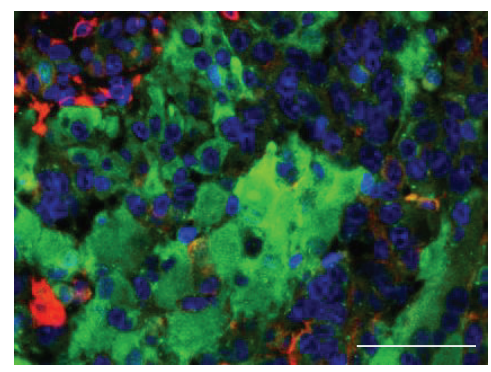

(f)

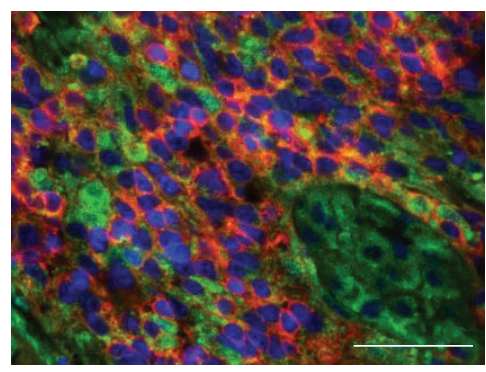

(i)

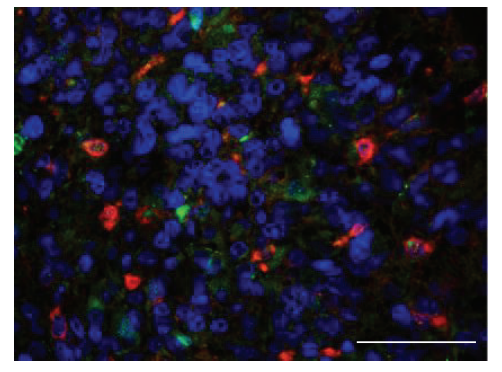

(1)

FIgURE 4: Double immunofluorescence staining for EGFR (a, d, g, and j; red stain) and Beclinl (b, e, h, and k; green stain). Representative GBs showing H-EGFR + L-Beclin1 (a, b, and c), L-EGFR + H-Beclin1 (d, e, and f), H-EGFR + H-Beclin1 (g, h, and i), and L-EGFR + L-Beclin1 $(\mathrm{j}, \mathrm{k}$, and $\mathrm{l})$ patterns of protein expression. Nuclei are marked by staining with 4,6-diamidino-2-phenylindole (DAPI) and appear blue in the merged pictures (c, f, i, and l). Original magnification $\times 650$. Scale bar $=50 \mu \mathrm{m}$.

a median survival of 30 months, compared to 18 months of L-EGFR, 15 months of H-Beclin1, and 11 months of all GBs (Figure 9).

3.7.2. Cox Regression Proportional Hazards Regression Multivariate Analysis. Given the dependency of the clini$\mathrm{cal} /$ therapeutic factors on the relationship with EGFR and Beclin1 expression (Table 1), the multivariate analysis of survival factors evidenced that H-EGFR (HR: 2.21; 95\% CI:
1.404-3.481; $P=0.001$ ), L-Beclin1 (HR: 1,898; 95\% CI: $1.244-$ 2.896; $P=0.003$ ), and B-STR (HR: 3,119; CI: 1.711-5.669; $P=0.0001)$ were independently associated with a shorter survival.

\section{Discussion}

Glioblastoma has a poor prognosis. Patients under current therapies have a median survival of approximately one year 
TABLE 1: Distribution of patient in each category, on account of clinical parameters and in each L/H-EGFR and L/H-Beclinl protein expression group. Significant $(P<0.05)$ correlations with clinical parameters are also given for each EGFR and Beclinl expression group, and in LEGFR + H-Beclin1 versus all the other expression groups in regard of both these proteins. Objective Response (OR) was considered Complete Radiological Response plus Partial Radiological Response.

\begin{tabular}{|c|c|c|c|}
\hline & $\begin{array}{c}\text { L-EGFR } \\
N^{\circ} \text { pts }\end{array}$ & $\begin{array}{c}\text { H-EGFR } \\
N^{\circ} \text { pts }\end{array}$ & $P$-value \\
\hline \multicolumn{4}{|l|}{ KPS } \\
\hline $100-80$ & 43 & 48 & \\
\hline$<70$ & 6 & 20 & 0.03 \\
\hline \multicolumn{4}{|l|}{ NPS } \\
\hline class 1 & 13 & 7 & \\
\hline class 2 & 20 & 21 & \\
\hline class 3 & 10 & 24 & \\
\hline class 4 & 6 & 16 & 0.002 \\
\hline \multicolumn{4}{|l|}{ Syncronous Multifocality } \\
\hline Yes & 3 & 16 & \\
\hline No & 46 & 52 & 0.01 \\
\hline \multicolumn{4}{|l|}{ Radiological Response } \\
\hline Complete Response & 10 & 9 & \\
\hline Partial Response (OR) & $17(27)$ & $9(18)$ & \\
\hline Stable Disease & 10 & 15 & 0.013 \\
\hline \multirow[t]{2}{*}{ Progressive Disease } & 12 & 35 & \\
\hline & $\begin{array}{c}\text { H-Beclin } 1 \\
N^{\circ} \text { pts }\end{array}$ & $\begin{array}{c}\text { L-Beclin } 1 \\
N^{\circ} \text { pts }\end{array}$ & $P$-value \\
\hline \multicolumn{4}{|l|}{ KPS } \\
\hline $100-80$ & 51 & 40 & \\
\hline$<70$ & 7 & 19 & 0.009 \\
\hline \multicolumn{4}{|l|}{ Radiological Response } \\
\hline Complete Response & 14 & 5 & \\
\hline Partial sdResponse (OR) & $19(33)$ & $7(12)$ & \\
\hline Stable Disease & 14 & 11 & 0.009 \\
\hline \multirow[t]{2}{*}{ Progressive Disease } & 11 & 36 & \\
\hline & L-EGFR + H-Beclin1 & All the other GBs & $P$-value \\
\hline \multicolumn{4}{|l|}{ KPS } \\
\hline $100-80$ & 24 & 67 & \\
\hline$<70$ & 0 & 26 & 0.03 \\
\hline \multicolumn{4}{|l|}{ NPS } \\
\hline class 1 & 9 & 11 & \\
\hline class 2 & 9 & 32 & \\
\hline class 3 & 5 & 29 & \\
\hline class 4 & 1 & 21 & 0.002 \\
\hline \multicolumn{4}{|l|}{ Syncronous Multifocality } \\
\hline Yes & 0 & 19 & \\
\hline No & 24 & 74 & 0.002 \\
\hline \multicolumn{4}{|l|}{ Radiological Response } \\
\hline Complete Response & 13 & 6 & \\
\hline Partial Response (OR) & $8(21)$ & $18(24)$ & \\
\hline Stable Disease & 3 & 22 & \\
\hline Progressive Disease & 0 & 47 & 0.013 \\
\hline
\end{tabular}




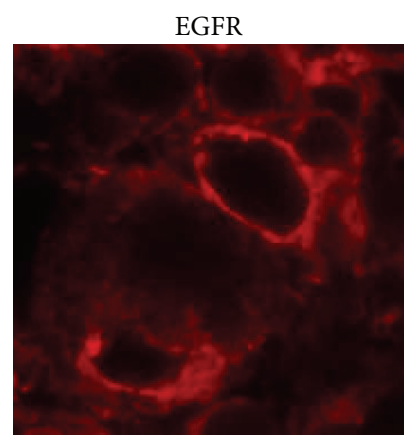

(a)

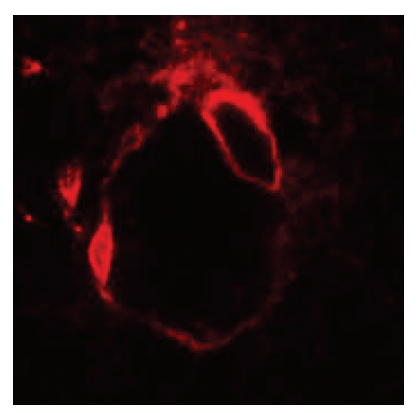

(d)

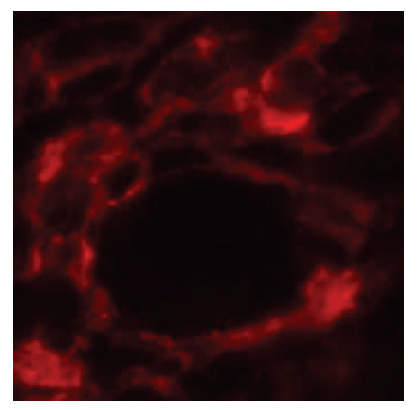

$(\mathrm{g})$

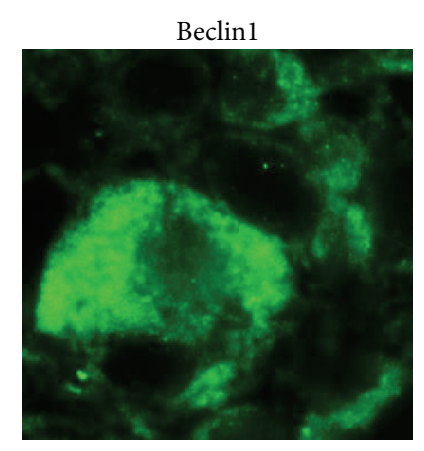

(b)

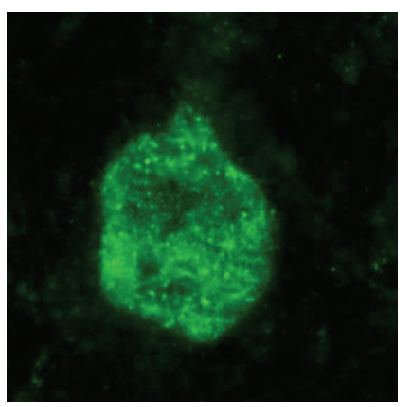

(e)

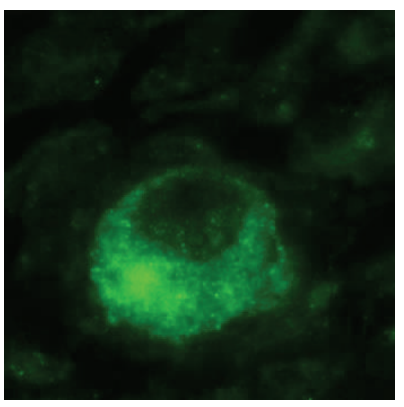

(h)

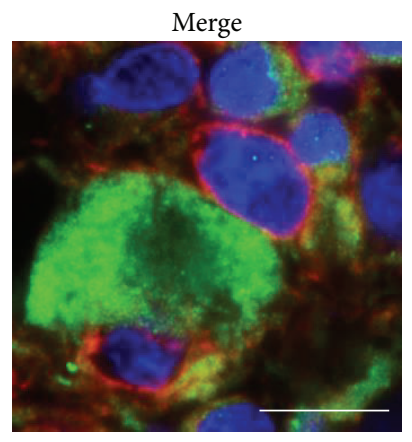

(c)

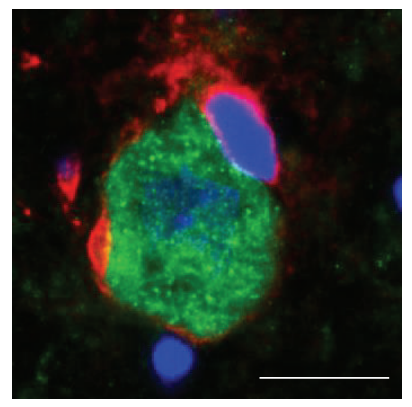

(f)

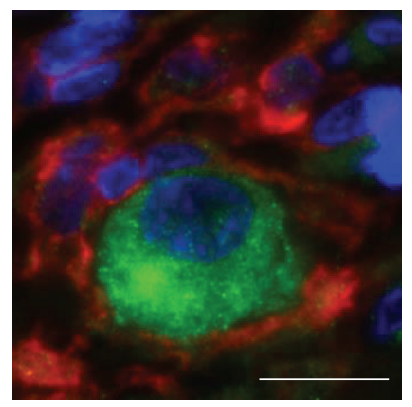

(i)

Figure 5: Double immunofluorescence staining. An admixture of H-EGFR (a, d, and g; red stain) and H-Beclin1 (b, e, and h; green stain) positive GB cells is observable in areas showing a heterogeneous pattern of protein expression. The merged pictures (c, $f$, and $i)$, however, show that the positivity is mutually exclusive; a pin point cytoplasmic positivity for Beclin1 is evident in these enlarged details of Figure 2. Scale bar $=25 \mu \mathrm{m}$.

after diagnosis, and it rarely exceeds 15 months for patients enrolled in clinical trials [5]. An increased efficacy of the standard of care was recently achieved, in fact, with TMZ concomitant and adjuvant in respect to radiotherapy [32, 33]. However, response to therapy and prognosis highly depends on both clinical and molecular determinants. Clinical trials as well as retrospective case series analyses outline the prognostic profile of subgroups of patients with a more favorable outcome, based on classical factors (i.e., young age, a good KPS and NPS, circumscribed neoplasms arising in noneloquent areas allowing for a gross total resection, and a high RT dose, i.e., 60 Gy $[2,34])$, which were all associated with a better prognosis also in our series, novel chemoradiotherapeutic approaches [33], and molecular biomarkers (i.e., themethylation of O6-methylguanine-DNA methyltransferase (MGMT) gene promoter [32] and mutations of isocitrate dehydrogenase
(IDH1) gene [35]). We also found a significant correlation of MGMT methylation with a longer survival, although the analysis was not conducted in all the cases. The network of prognostic factors is continuously growing and large-scale genome analyses are further subgrouping molecular subtypes of GB associated with different prognosis [3, 7]. However, to date, among molecular biomarkers, only the MGMT promoter methylation status predictive biomarker has an undoubtedly high impact on clinical practice, being used for stratification of RT and TMZ-CHT treatment regimes, leading to a limited but significant improvement of survival $[32,34]$.

Therefore, further molecular prognostic biomarkers and targets for identifying patients at a higher prognostic risk are needed, for enlarging the horizon of future individualized therapies. 
TABLE 2: Clinical (Age = age at diagnosis, NPS $=$ Neurological Performance Status, KPS $=$ Karnofsky Performance Status), treatment $($ GTR $=$ Macroscopic Gross Total Resection, B/STR = Biopsy or Sub-Total Tumor Resection, Dose RT = total dose for radiotherapy treatment, Sequential CHT = TMZ, sequentially administered after the RT-TMZ concomitant course), and biological (EGFR expression and Beclin1 expression) prognostic factors (Kaplan-Meier method, Survival Analysis).

\begin{tabular}{|c|c|c|c|c|c|}
\hline & $n^{\circ} \mathrm{pts}$ & $\begin{array}{l}\text { Progression Disease } \\
\text { Free Survival }\end{array}$ & $P$-value & Overall Survival & $P$-value \\
\hline & & Median (months) & & Median (months) & \\
\hline \multicolumn{6}{|l|}{ Age } \\
\hline$>50$ & 102 & 7 & 0.035 & 11 & 0.04 \\
\hline$<50$ & 15 & 17 & & 18 & \\
\hline \multicolumn{6}{|l|}{ NPS } \\
\hline class 1 & 20 & 10 & & 15 & \\
\hline class 2 & 41 & 4 & 0.0001 & 18 & 0.0001 \\
\hline class 3 & 34 & 3 & & 11 & \\
\hline class 4 & 22 & 1 & & 5 & \\
\hline \multicolumn{6}{|l|}{ KPS } \\
\hline $100-80$ & 91 & 9 & 0.001 & 15 & 0.0001 \\
\hline$<70$ & 26 & 2 & & 5 & \\
\hline \multicolumn{6}{|l|}{ Extent of Surgery } \\
\hline GTR & 23 & 17 & 0.003 & 30 & 0.001 \\
\hline $\mathrm{B} / \mathrm{STR}$ & 94 & 5 & & 10 & \\
\hline \multicolumn{6}{|l|}{ Dose RT } \\
\hline$<54$ Gy & 36 & 3 & 0.04 & 5 & 0.033 \\
\hline $54-60 \mathrm{~Gy}$ & 57 & 7 & & 18 & \\
\hline$>60 \mathrm{~Gy}$ & 24 & 10 & & 16 & \\
\hline \multicolumn{6}{|l|}{ Sequential CHT } \\
\hline yes & 61 & 9 & 0.0001 & 15 & 0.0001 \\
\hline no & 56 & 1 & & 5 & \\
\hline \multicolumn{6}{|c|}{ Synchronous Multifocality } \\
\hline yes & 19 & 4 & 0.002 & 7 & 0.001 \\
\hline no & 98 & 10 & & 15 & \\
\hline \multicolumn{6}{|l|}{ MGMT status } \\
\hline Methylated & 38 & 20 & 0.002 & 22 & 0.003 \\
\hline Unmethylated & 45 & 4 & & 5 & \\
\hline \multicolumn{6}{|l|}{ EGFR expression } \\
\hline Low & 49 & 14 & 0.002 & 18 & 0.004 \\
\hline High & 68 & 5 & & 9 & \\
\hline \multicolumn{6}{|c|}{ Beclin-1 expression } \\
\hline High & 58 & 12 & 0.001 & 15 & 0.001 \\
\hline Low & 59 & 4 & & 5 & \\
\hline \multicolumn{6}{|c|}{ EGFR and Beclin1 co-expression } \\
\hline $\begin{array}{l}\text { L-EGFR } \\
\text { H-Beclin1 }\end{array}$ & 24 & 22 & 0.001 & 30 & 0.001 \\
\hline Others & 93 & 8 & & 11 & \\
\hline
\end{tabular}

Our study suggests that the combined evaluation of EGFR and Beclinl autophagic protein expression in tumor tissue sections could add valuable information to the prognostic molecular profile of GB.
In our experience, in fact, multivariate analysis indicated that, combining the two variables, that is, L-EGFR and $\mathrm{H}$ Beclinl expression, a subgroup of patients (20.4\%) with a more favorable prognosis could be identified. This subgroup 


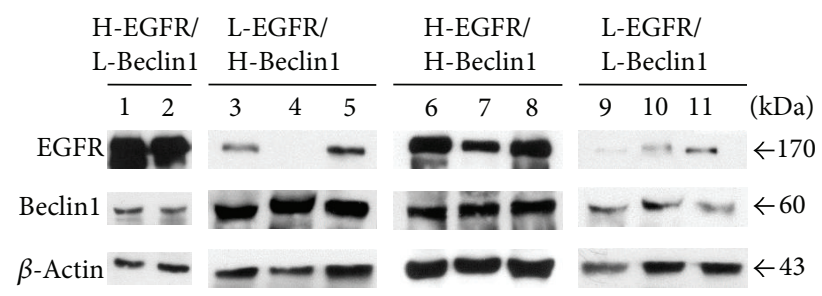

(a)

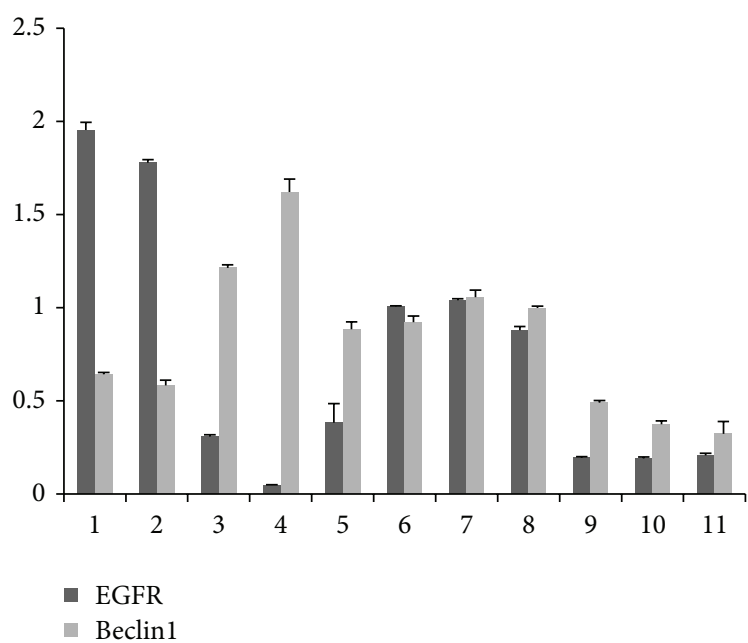

(b)

Figure 6: (a) Western blotting for EGFR (170 kDa) and Beclin1 $(60 \mathrm{kDa})$ in representative H-EGFR/L-Beclin1 (lanes 1 and 2), LEGFR/H-Beclinl (lanes 3-5), H-EGFR/H-Beclinl (lanes 6-8), and L-EGFR/L-Beclin1 (lanes 9-11) GBs. (b) Up- or downregulation of either EGFR or Beclin1 is quantified by densitometric data analysis, which shows the relative expression of EGFR and Beclinl after normalization to the $\beta$-actin bands. Data are reported as means \pm S.E. of three densitometric analyses of the same sample.

of GB patients reached a median survival of 30 months compared to 11 months of all the 117 cases, 18 months of LEGFR, and 15 months of H-Beclin1 protein expressing GB subgroups. Furthermore, EGFR/Beclin1 protein expression identified subgroups of GB patients with a different clinical presentation, in terms of clinical and neurological patient status and multifocality of lesions and edema, and with MRI radiological evidence of response to therapy, in terms of ORs. The worst clinical set was associated with a H-EGFR and the best with a L-EGFR + H-Beclin1 protein expression profile. In the latter group, in particular, in no case was there multifocality of the neoplasm at onset.

EGFR protein overexpression and gene mutation/amplification are known drivers of gliomagenesis and GB aggressiveness, activating signaling cascades that trigger tumor cell proliferation and invasiveness, angiogenesis, and suppressing apoptotic cell death [20,36-39], largely contributing to the high RT-CHT therapy resistant GB phenotype $[6,39,40]$. EGFR alterations are found in most GBs and characterize the most frequent molecular classic subtype [3], thus being an ideal targetable molecule. However, the use of monoclonal antibodies for therapy has not yielded promising results

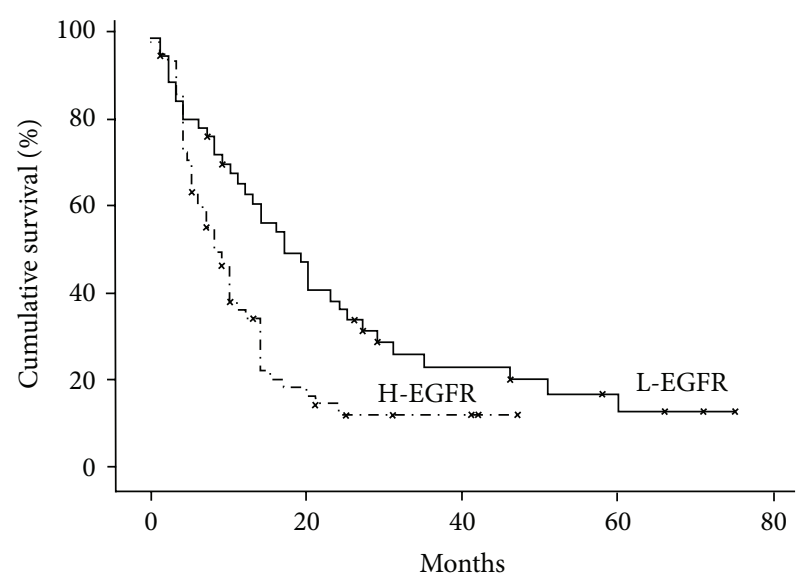

FIGURE 7: Kaplan-Meier survival curves for EGFR expression levels $(P$ value $<0.05)$.

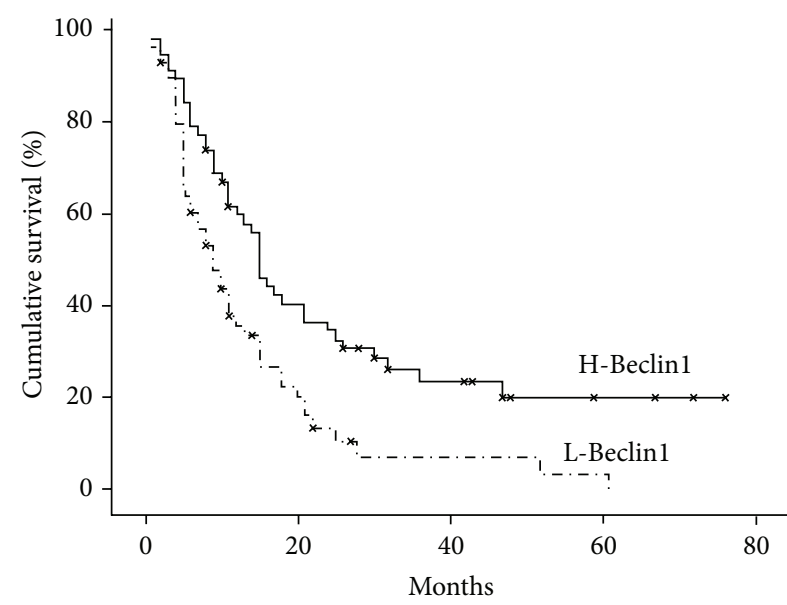

FIGURE 8: Kaplan-Meier survival curves for Beclin1 expression levels $(P$ value $<0.05)$.

to date in clinical trials [41]. Novel strategies are intended to target the key phosphorylated kinases and/or altered metabolic pathways downstream EGFR [41]. Autophagy is one of the altered metabolic pathways inhibited by EGFR, which acts via mTOR [8] or by direct inhibition of Beclin1, a cytoplasmic protein that induces autophagy by binding to Vps34-Vps15 core $[8,18,19,42]$. It is known that this catabolic process acts as a tumor suppressor in the early phases of carcinogenesis, while, in advanced neoplasms, depending on tumor cell context and type, it may either promote or inhibit cancer progression and therapy resistance, being also able to induce an autophagy-related or type II programmed tumor cell death [11]. The authors [22], as others [23], found that Beclin1 was underexpressed in most GBs: this was associated with a decreased apoptosis and negatively impacted on prognosis [24]. The overall negative impact of activated EGFR on autophagy could partly explain the alternate, almost mutually exclusive expression of EGFR and Beclinl that we observed in most GBs. By examining the colocalization of the two proteins with a double immunofluorescence 


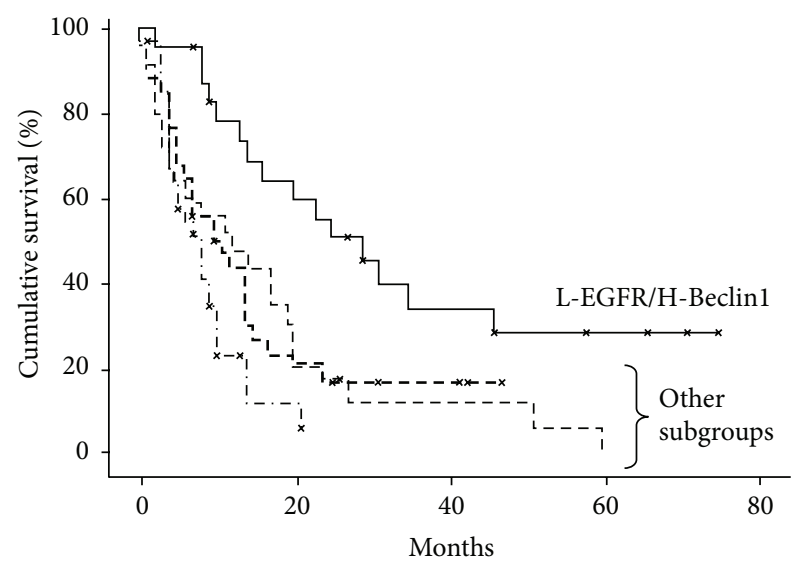

Figure 9: Kaplan-Meier survival curves for EGFR and Beclin1 coexpression $(P$ value $<0.05)$.

stain, in areas showing heterogenous protein expression, cells positive for EGFR were negative for Beclinl and vice versa.

EGFR's direct inhibition of Beclinl and/or the existence of mutated forms of Beclinl recently observed in human nonsmall cell lung carcinoma cells [19], in which EGFR was found colocalized with Beclinl in autophagic vacuoles, support the coexpression of the two proteins that we also observed in GB cells. The distribution of the two proteins was, in fact, heterogenous in many cases, although subgroups of GBs could be identified based on the dominant protein expression pattern. Other unknown-to-us factors may occur in cases in which both proteins were negative. Synchronous multifocality of newly diagnosed GBs and GB aggressiveness are partly linked to the invasion ability of neoplastic cells, resulting from an orchestrated activation of cell migration, in which EGFR plays a pivotal role [38, 43-45].

Low expression of Beclin1 was also related to distant metastasis risk in breast cancer [46] and recently we demonstrated that the combined silencing of EGFR and induction of autophagy by rapamycin has additive effects both in increasing radiation sensitivity and in inhibiting cell migration ability, in U373 and T98G GB cells [25]. Therefore, both LEGFR and H-Beclinl might have interacted in contributing to the minor aggressiveness, the higher MRI evaluated response to therapy, and the lack of multifocal presentation, which we observed in the GB group with a more favorable prognosis, whereas the leading EGFR ability on cellular invasiveness may partly justify why H-EGFR patients showed a significantly higher multifocal presentation, besides a more frequent progression of the disease at imaging after treatment and a poorer prognosis.

MGMT methylation was positively correlated with prognosis. However, it was not correlated with either EGFR or Beclin1 expression, further supporting their independent role as prognosis biomarkers, despite the fact that MGMT analysis was not performed in all our GB cases.

\section{Conclusion}

Our results provide a preliminary assessment of the role of EGFR and Beclin1, extrapolated from a series of GB patients treated according to a prospectively definite protocol. Some correlations, in terms of clinical features at referral, imaging data, response to RT-TMZ treatment, and survival, can be established with EGFR and Beclinl expression. In particular, some parameters of aggressiveness in GBs, such as multifocality (probably related to tumor cell invasiveness) and the type of response to postoperative treatment, deserve further study with regard to these relationships, in our opinion. It is noteworthy that a combined L-EGFR and HBeclin1 GB profile seems to identify, in our observations, a subgroup of long-surviving patients. This new disclosure might contribute to the other available data suitable for prognostic stratification of GB patients and also envisage future implications for targeted therapies.

\section{Conflict of Interests}

The authors declare that there is no conflict of interests regarding the publication of this paper.

\section{References}

[1] National Comprehensive Cancer Network, National Comprehensive Cancer Network Guidelines, 2014.

[2] W. J. Curran Jr., C. B. Scott, J. Horton et al., "Recursive partitioning analysis of prognostic factors in three radiation therapy oncology group malignant glioma trials," Journal of the National Cancer Institute, vol. 85, no. 9, pp. 704-710, 1993.

[3] R. G. W. Verhaak, K. A. Hoadley, E. Purdom et al., "Integrated genomic analysis identifies clinically relevant subtypes of glioblastoma characterized by abnormalities in PDGFRA, IDH1, EGFR, and NF1," Cancer Cell, vol. 17, no. 1, pp. 98-110, 2010.

[4] C. W. Brennan, R. G. Verhaak, A. McKenna et al., "The somatic genomic landscape of glioblastoma," Cell, vol. 155, no. 2, pp. 462-477, 2013.

[5] M. Preusser, S. de Ribaupierre, A. Wöhrer et al., "Current concepts and management of glioblastoma," Annals of Neurology, vol. 70, no. 1, pp. 9-21, 2011.

[6] A. Chakravarti, A. Dicker, and M. Mehta, "The contribution of epidermal growth factor receptor (EGFR) signaling pathway to radioresistance in human gliomas: a review of preclinical and correlative clinical data," International Journal of Radiation Oncology Biology Physics, vol. 58, no. 3, pp. 927-931, 2004.

[7] R. Shen, Q. Mo, N. Schultz et al., "Integrative subtype discovery in glioblastoma using iCluster," PLoS ONE, vol. 7, no. 4, Article ID e35236, 2012

[8] J. Yan, H. Yang, G. Wang et al., "Autophagy augmented by troglitazone is independent of EGFR transactivation and correlated with AMP-activated protein kinase signaling," Autophagy, vol. 6, no. 1, pp. 67-73, 2010.

[9] B. Levine and D. J. Klionsky, "Development by self-digestion: molecular mechanisms and biological functions of autophagy," Developmental Cell, vol. 6, no. 4, pp. 463-477, 2004.

[10] Z. J. Yang, C. E. Chee, S. Huang, and F. A. Sinicrope, "The role of autophagy in cancer: therapeutic implications," Molecular Cancer Therapeutics, vol. 10, no. 9, pp. 1533-1541, 2011. 
[11] D. C. Rubinsztein, P. Codogno, and B. Levine, "Autophagy modulation as a potential therapeutic target for diverse diseases," Nature Reviews Drug Discovery, vol. 11, no. 9, pp. 709-730, 2012.

[12] J. N. Sarkaria, E. Galanis, W. Wu et al., "North central cancer treatment group Phase i trial N057K of everolimus (RAD001) and temozolomide in combination with radiation therapy in patients with newly diagnosed glioblastoma multiforme," International Journal of Radiation Oncology Biology Physics, vol. 81, no. 2, pp. 468-475, 2011.

[13] S. Palumbo, L. Pirtoli, P. Tini et al., "Different involvement of autophagy in human malignant glioma cell lines undergoing irradiation and temozolomide combined treatments," Journal of Cellular Biochemistry, vol. 113, no. 7, pp. 2308-2318, 2012.

[14] T. Kanzawa, I. M. Germano, T. Komata, H. Ito, Y. Kondo, and S. Kondo, "Role of autophagy in temozolomide-induced cytotoxicity for malignant glioma cells," Cell Death and Differentiation, vol. 11, no. 4, pp. 448-457, 2004.

[15] W. Zhuang, Z. Qin, and Z. Liang, "The role of autophagy in sensitizing malignant glioma cells to radiation therapy," Acta Biochimica et Biophysica Sinica, vol. 41, no. 5, pp. 341-351, 2009.

[16] V. Nikoletopoulou, M. Markaki, K. Palikaras, and N. Tavernarakis, "Crosstalk between apoptosis, necrosis and autophagy," Biochimica et Biophysica Acta, vol. 1833, no. 12, pp. 3448-3459, 2013.

[17] S. Palumbo and S. Comincini, "Autophagy and ionizing radiation in tumors: the "survive or not survive" dilemma," Journal of Cellular Physiology, vol. 228, no. 1, pp. 1-8, 2013.

[18] R. Kang, H. J. Zeh, M. T. Lotze, and D. Tang, "The Beclin 1 network regulates autophagy and apoptosis," Cell Death and Differentiation, vol. 18, no. 4, pp. 571-580, 2011.

[19] Y. Wei, Z. Zou, N. Becker et al., "XEGFR-mediated beclin 1 phosphorylation in autophagy suppression, tumor progression, and tumor chemoresistance," Cell, vol. 154, no. 6, pp. 1269-1284, 2013.

[20] M. Lund-Johansen, R. Bjerkvig, P. A. Humphrey, S. H. Bigner, D. D. Bigner, and O.-D. Laerum, "Effect of epidermal growth factor on glioma cell growth, migration, and invasion in vitro," Cancer Research, vol. 50, no. 18, pp. 6039-6044, 1990.

[21] F. G. Barker II, M. L. Simmons, S. M. Chang et al., "EGFR overexpression and radiation response in glioblastoma multiforme," International Journal of Radiation Oncology Biology Physics, vol. 51, no. 2, pp. 410-418, 2001.

[22] C. Miracco, E. Cosci, G. Oliveri et al., "Protein and mRNA expression of autophagy gene Beclin 1 in human brain tumours," International Journal of Oncology, vol. 30, no. 2, pp. 429-436, 2007.

[23] X. Huang, H. M. Bai, L. Chen, B. Li, and Y. C. Lu, "Reduced expression of LC3B-II and Beclin 1 in glioblastoma multiforme indicates a down-regulated autophagic capacity that relates to the progression of astrocytic tumors," Journal of Clinical Neuroscience, vol. 17, no. 12, pp. 1515-1519, 2010.

[24] L. Pirtoli, G. Cevenini, P. Tini et al., "The prognostic role of Beclin 1 protein expression in high-grade gliomas," Autophagy, vol. 5, no. 7, pp. 930-936, 2009.

[25] S. Palumbo, P. Tini, M. Toscano et al., "Combined EGFR and autophagy modulation impairs cell migration and enhances radiosensitivity in human glioblastoma cells," Journal of Cellular Physiology, vol. 229, no. 11, pp. 1863-1873, 2014.

[26] D. N. Louis, H. Ohgaki, O. D. Wiestler, and W. K. Cavenee, WHO Classification of Tumours of the Central Nervous System, IARC, Lyon, France, 2007.
[27] L. Pirtoli, G. Rubino, S. Marsili et al., “Three-dimensional conformal radiotherapy, temozolomide chemotherapy, and highdose fractionated stereotactic boost in a protocol-driven, postoperative treatment schedule for high-grade gliomas," Tumori, vol. 95, no. 3, pp. 329-337, 2009.

[28] ICRU, "International Commission on Radiation Units and Measurements. Prescribing, recording, and reporting photon beam therapy, Supplement to ICRU Report No. 50," ICRU Report 62, ICRU, Bethesda, Md, USA, 1999.

[29] "Prognostic factors for high-grade malignant glioma : development of a prognostic index . A Report of the Medical Research Council Brain Tumour Working Party," Journal of NeuroOncology, vol. 9, no. 1, pp. 47-55, 1990.

[30] D. R. Macdonald, T. L. Cascino, S. C. Schold Jr., and J. G. Cairncross, "Response criteria for phase II studies of supratentorial malignant glioma," Journal of Clinical Oncology, vol. 8, no. 7, pp. 1277-1280, 1990.

[31] P. Y. Wen, D. R. Macdonald, D. A. Reardon et al., "Updated response assessment criteria for high-grade gliomas: response assessment in neuro-oncology working group," Journal of Clinical Oncology, vol. 28, no. 11, pp. 1963-1972, 2010.

[32] M. E. Hegi, A.-C. Diserens, T. Gorlia et al., "MGMT gene silencing and benefit from temozolomide in glioblastoma," The New England Journal of Medicine, vol. 352, no. 10, pp. 997-1003, 2005.

[33] R. Stupp, M. E. Hegi, B. Neyns et al., "Phase I/IIa study of cilengitide and temozolomide with concomitant radiotherapy followed by cilengitide and temozolomide maintenance therapy in patients with newly diagnosed glioblastoma," Journal of Clinical Oncology, vol. 28, no. 16, pp. 2712-2718, 2010.

[34] S. M. Magrini, U. Ricardi, R. Santoni et al., "Patterns of practice and survival in a retrospective analysis of 1722 adult astrocytoma patients treated between 1985 and 2001 in 12 Italian radiation oncology centers," International Journal of Radiation Oncology Biology Physics, vol. 65, no. 3, pp. 788-799, 2006.

[35] C. Hartmann, B. Hentschel, W. Wick et al., "Patients with IDH1 wild type anaplastic astrocytomas exhibit worse prognosis than IDH1-mutated glioblastomas, and IDH1 mutation status accounts for the unfavorable prognostic effect of higher age: implications for classification of gliomas," Acta Neuropathologica, vol. 120, no. 6, pp. 707-718, 2010.

[36] M. Nagane, F. Coufal, H. Lin, O. Bögler, W. K. Cavenee, and H.-J. S. Huang, "A common mutant epidermal growth factor receptor confers enhanced tumorigenicity on human glioblastoma cells by increasing proliferation and reducing apoptosis," Cancer Research, vol. 56, no. 21, pp. 5079-5086, 1996.

[37] B. Li, M. Yuan, I. A. Kim, C. M. Chang, E. J. Bernhard, and H. K. G. Shu, "Mutant epidermal growth factor receptor displays increased signaling through the phosphatidylinositol3 kinase/AKT pathway and promotes radioresistance in cells of astrocytic origin," Oncogene, vol. 23, no. 26, pp. 4594-4602, 2004.

[38] T. E. van Meter, W. C. Broaddus, H. K. Rooprai, G. J. Pilkington, and H. L. Fillmore, "Induction of membrane-type-1 matrix metalloproteinase by epidermal growth factor-mediated signaling in gliomas," Neuro-Oncology, vol. 6, no. 3, pp. 188-199, 2004.

[39] K. J. Hatanpaa, S. Burma, D. Zhao, and A. A. Habib, "Epidermal growth factor receptor in glioma: signal transduction, neuropathology, imaging, and radioresistance," Neoplasia, vol. 12, no. 9, pp. 675-684, 2010.

[40] A. Chakravarti, A. Chakladar, M. A. Delaney, D. E. Latham, and J. S. Loeffler, "The epidermal growth factor receptor pathway 
mediates resistance to sequential administration of radiation and chemotherapy in primary human glioblastoma cells in a RAS-dependent manner," Cancer Research, vol. 62, no. 15, pp. 4307-4315, 2002.

[41] B. Kalman, E. Szep, F. Garzuly, and D. E. Post, "Epidermal growth factor receptor as a therapeutic target in glioblastoma," NeuroMolecular Medicine, vol. 15, no. 2, pp. 420-434, 2013.

[42] Z. Yang and D. J. Klionsky, "Eaten alive: a history of macroautophagy," Nature Cell Biology, vol. 12, no. 9, pp. 814-822, 2010.

[43] G. Maheshwari, A. Wells, L. G. Griffith, and D. A. Lauffenburger, "Biophysical integration of effects of epidermal growth factor and fibronectin on fibroblast migration," Biophysical Journal, vol. 76, no. 5, pp. 2814-2823, 1999.

[44] A. Wells, "Tumor Invasion: role of growth factor-induced cell motility," Advances in Cancer Research, vol. 78, pp. 31-101, 1999.

[45] A. Wells, J. Kassis, J. Solava, T. Turner, and D. A. Lauffenburger, "Growth factor-induced cell motility in tumor invasion," Acta Oncologica, vol. 41, no. 2, pp. 124-130, 2002.

[46] M. Dong, X.-B. Wan, Z. Y. Yuan et al., "Low expression of Beclin 1 and elevated expression of HIF- $1 \alpha$ refine distant metastasis risk and predict poor prognosis of ER-positive, HER2-negative breast cancer," Medical Oncology, vol. 30, no. 1, article 355, 2013. 


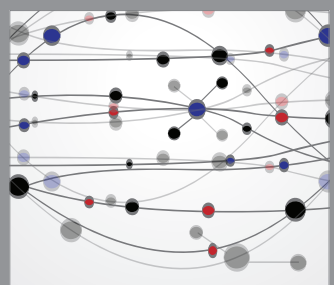

The Scientific World Journal
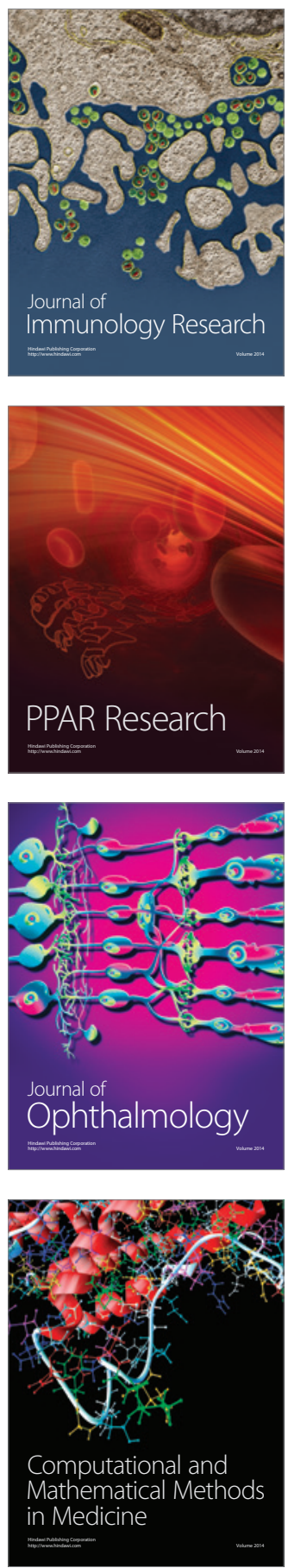

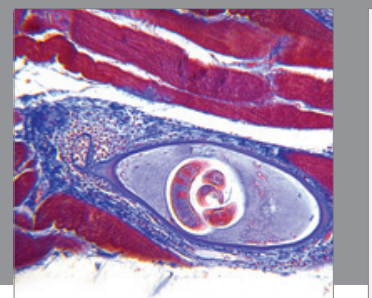

Gastroenterology

Research and Practice
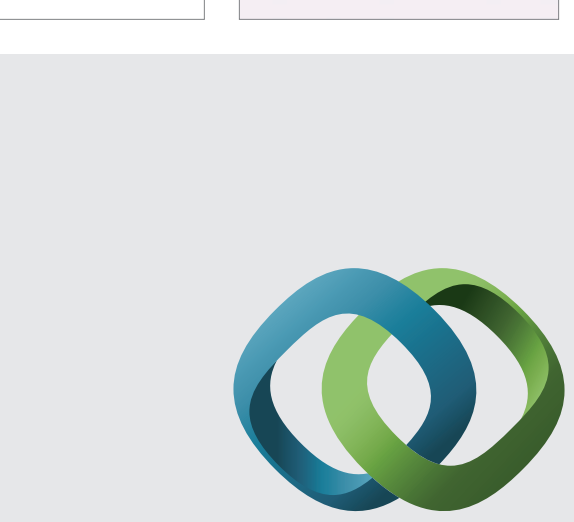

\section{Hindawi}

Submit your manuscripts at

http://www.hindawi.com
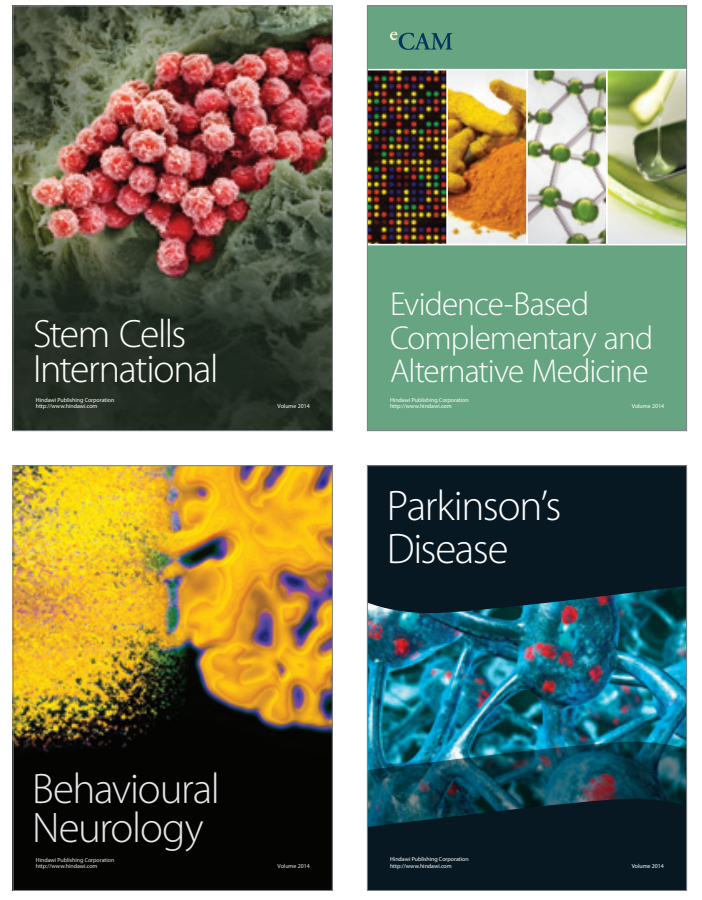
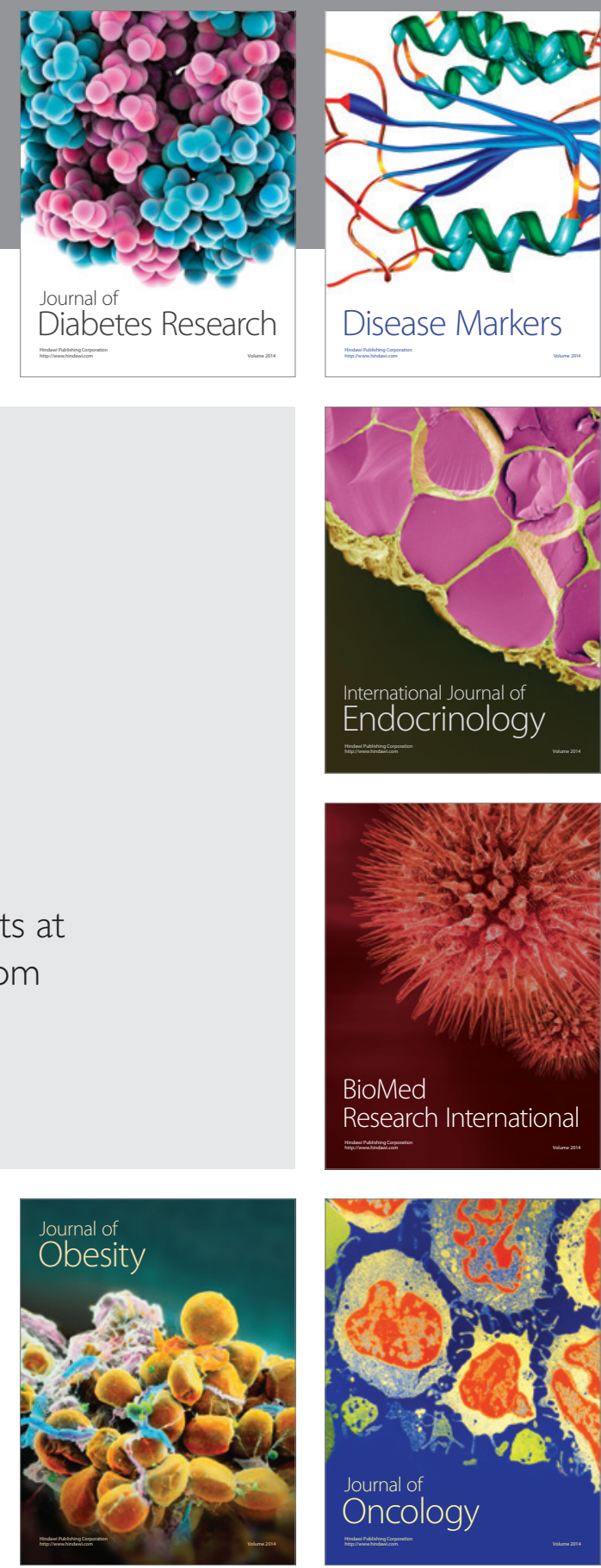

Disease Markers
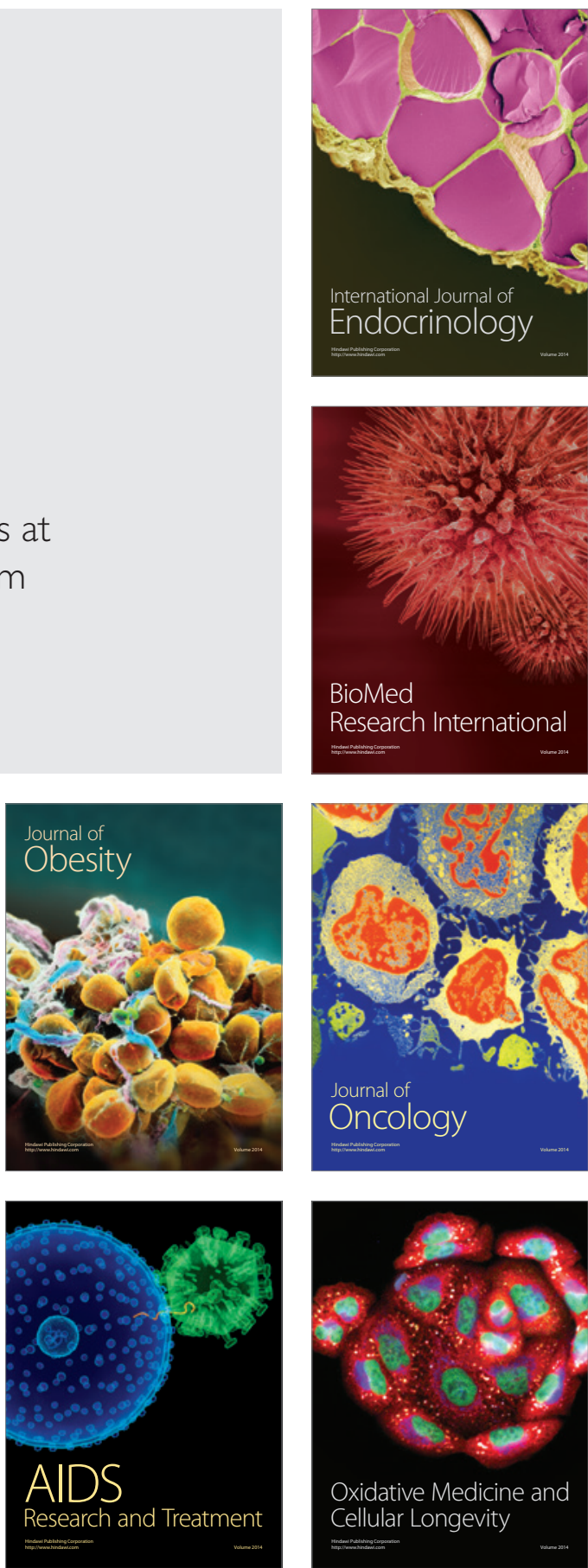